\title{
THE EFFECT OF INCREASING THE AIR FLOW PRESSURE ON THE PROPERTIES OF COATINGS DURING THE ARC SPRAYING OF CORED WIRES
}

\section{STUDENT Mykhailo', GVOZDETSKY Volodymyr ${ }^{1}$, STUDENT Oleksandra ${ }^{1}$, PRENTKOVSKIS Olegas ${ }^{2}$, MARUSCHAK Pavlo ${ }^{3}$, OLENYUK Olena ${ }^{4}$, TITOVA Liudmyla ${ }^{5}$}

\author{
${ }^{1}$ Karpenko Physico-Mechanical Institute of the National Academy of Sciences of Ukraine, \\ Naukova 5, 579060, Lviv Ukraine \\ ${ }^{2}$ Vilnius Gediminas Technical University, Plytinès g. 27, Vilnius LT-10105, Lithuania \\ ${ }^{3}$ Ternopil Ivan Puluj National Technical University, Ruska 56, 46001, Ternopil, Ukraine, \\ e-mail: maruschak.tu.edu@gmail.com \\ ${ }^{4}$ Franko National University of Lviv, Universytetska st., 1, 79000, Lviv, Ukraine \\ ${ }^{5}$ National University of Life and Environmental Sciences of Ukraine, \\ Heroiv Oborony str.15, 03041, Kyiv, Ukraine
}

\begin{abstract}
The melting conditions of the electrode wires and the structure of coatings, obtained by the electric arc spraying method depending on the pressure of the spraying air flow, are analysed in the current paper. The effect of air pressure on the spraying angle of the flow of melted metal droplets is demonstrated. It is established that due to the decrease in this spraying angle, the temperature of the droplets increases. In addition, high-speed airflow is more easily captured by smaller molten metal droplets and during the contact with the substrate surface their deformations were more strongly. Due to such phenomenon, the porosity of the coatings was reduced and the number of lamellae, welded to each other, increased. With the increasing pressure of the air flow, the thicknesses of the lamellae were decreased, however, the amount of the oxide phase in the coatings has increased. As a result, the hardness, wear resistance and cohesive strength of the coatings, obtained at a higher pressure of the air flow, have increased; and the level of residual stresses of the first kind in them decreased.
\end{abstract}

KEYWORDS: cored wires, lamellar structure of coating, mechanical and physical properties of coatings, oxide films

\section{$1 \quad$ Introduction}

Technologically, the method of arc spray metallization (ASM) is considered as the simplest and cheapest to obtain coatings, in comparison with the known gas-thermal methods [1-3]. Recently, it has been started to the use the electrode materials in the form of special cored wires $(\mathrm{CW})$ for their creation. This made it possible to expand the field of application of the ASM method and to obtain new restoration and protective coatings for various functional purposes with higher service characteristics [3-7]. However, arc spraying coatings (ASC) are characterized by high porosity within the range of 3.0\% - 5.0\%, high level of residual tensile stresses, low cohesion and adhesion (compared with coatings obtained by other gas-thermal methods) [8-11]. Therefore, in recent years, researches, which are directed to improve the physical and mechanical characteristics of coatings, deposited by the ASM method, have been intensified. So that to achieve the mentioned aim of the research, the compressed spraying air is replaced by a mixture of combustible gases with oxygen [12]. By increasing the speed of the molten metal droplets, forming the coatings, it has become possible to significantly improve their mechanical characteristics and reduce porosity. However, the implementation of this approach is accompanied by a significant complication of the design of spraying 
devices, a perceptible increase in energy consumptions and the total cost of the deposited coatings. From a technological point of view, it is much easier to increase the velocity of the particles of the molten metal by increasing the pressure of the sprayed air stream [13].

The aim of the paper is to investigate the effect of the molten metal droplets rate at the flight to the substrate during the implementation of the ASM method on the structure, mechanical characteristics and wear resistance of the obtained coatings.

\section{Experimental techniques}

All ASC with a thickness of $1 \mathrm{~mm}$ were obtained with a PMI-2 metallizer, developed at the Karpenko Physico-Mechanical Institute NAS of Ukraine. To obtain these coatings, the following electrode materials were used: the solid wire of the U8 steel and the eight types of the $\mathrm{CW}$ with their different cores charging, in particular: 1 - the mixture of the $\left(\mathrm{FeCr}+\mathrm{B}_{4} \mathrm{C}\right)$ powders (CW 70Cr18B3 type); 2 - the mixture of the $(\mathrm{FeCrB}+\mathrm{FeSi}$ ) powders $(\mathrm{CW}$ Cr18B3Si2 type); 3 - the mixture of the (FeCrB + AlMg) powders (CW Cr6B3Al3Mg2); 4 only $\mathrm{FeCrB}$ powder (CW 140Cr16B3 type); 5 - only FeCr powder (CW 140Cr14 type); 6 the mixture of $(\mathrm{FeCr}+\mathrm{FeF})$ powders $(\mathrm{CW} 140 \mathrm{Cr} 14 \mathrm{FeF}$ type $) ; 7$ - the mixture of the $(\mathrm{FeCr}+$ $\mathrm{FeTi}+\mathrm{Ni}+\mathrm{Al})$ powders $(\mathrm{CW}$ 140Cr14Ni2TiAl type); 8 - the mixture of the $(\mathrm{FeCr}+$ $\mathrm{FeCrB} \cdot \mathrm{FeTi}+\mathrm{Ni}$ ) powders $(\mathrm{CW} 140 \mathrm{Cr} 16 \mathrm{~B} 3 \mathrm{Ti} 2 \mathrm{Ni} 2$ type). The coatings were sprayed at the following parameters: voltage $U=32 \mathrm{~V}$, current $I=150 \mathrm{~A}$, air pressure $P=0.6$ and $1.2 \mathrm{MPa}$, air consumption $1.3 \mathrm{~m}^{3} / \mathrm{min}$, the distance to the spraying substrate $120 \mathrm{~mm}$. Before spraying, the specimens were treated by an abrasive-jet method using the corundum particles with a diameter of within the range of $3.0-5.0 \mathrm{~mm}$. The $\mathrm{HV}_{0.2}$ microhardness of obtained coatings was determined on a PMT-3 microhardness device at a load of $200 \mathrm{~g}$.

A Laval's nozzle with two vertically arranged air channels with the supersonic air flow velocity (with Mach number 2) was created. To calculate the characteristic dimensions of such nozzle, the formulas given in $[14,15]$ were used.

In particular, at each $i^{\text {th }}$ point along the length of such nozzle, the following parameters were calculated: the cross-sectional areas of channels for air flow $S_{i}=G /\left(\rho_{i} \cdot V_{i}\right)$ and their diameters $d_{i}=\left(4 \cdot S_{i} / \pi\right)^{1 / 2}, G$ - where air consumption per time unit $(\mathrm{kg} / \mathrm{s}), \rho_{i}-$ air density $\left(\mathrm{kg} / \mathrm{m}^{3}\right), V_{i}-$ air flow velocity $(\mathrm{m} / \mathrm{s})$; the lengths of subsonic $l_{1}=\left(d_{i}-d_{c r}\right) / 2 \cdot \operatorname{tg}\left(\alpha_{2} / 2\right)$ and supersonic $l_{2}=\left(d_{i}-d_{c r}\right) / 2 \cdot \operatorname{tg}\left(\alpha_{1} / 2\right)$ nozzle parts, respectively, de $\alpha_{1}$ and $\alpha_{2}$ - the angles in the subsonic and supersonic parts of a Laval's nozzle $\left({ }^{\circ}\right), d_{c r}-$ the diameter of the channel in the critical section of a nozzle at the transition to its supersonic parts. The air flow rate along the nozzle length was defined as $V_{i}=\left[2 k \cdot R\left(T_{0}-T_{i}\right) /(k-1)\right]^{1 / 2}$, where $k$ - the adiabatic characteristic $(k=1.4), R$ - the gas constant for air $(\mathrm{J} / \mathrm{kg} \cdot \mathrm{K}), T_{0}$ and $T_{i}$ - the temperatures of the air flow at the inlet to the subsonic part of a nozzle and along the length of its supersonic part, respectively $\left({ }^{\circ} \mathrm{C}\right)$. As a result of the calculations, the following characteristic sizes of a nozzle were obtained: $d_{c r}=2.2 \mathrm{~mm}, l_{1}=10 \mathrm{~mm}, l_{2}=15 \mathrm{~mm}$, that ensured $V_{i}$ changes the length of a Laval's nozzle as shown in Fig. 1.

The distance from the end of the nozzle to the arc was set $10 \mathrm{~mm}$. The rate of molten metal droplets dispersed by such air flow was experimentally determined using the technique of two rotating disks [12]. To determine the temperature on the substrate surface (5140 steel plates 5 $\mathrm{mm}$ thick) during ASC applying at both air pressure at the nozzle inlet (0.6 and 1.2 MPa), a thermocouple was attached at a depth of $4 \mathrm{~mm}$ inside the hole located on the opposite surface (relative to the sprayed one). All ASC were obtained by spraying the different electrode wires weighing $300 \mathrm{~g}$ during of the $30 \mathrm{~s}$ when using a fixed metalizer. The temperature on the substrate surface decreased in the direction from the centre of the spraying spot. With an air 
pressure of $0.6 \mathrm{MPa}$, the maximum temperature at spot centre is $450{ }^{\circ} \mathrm{C}$, and at a pressure of $1.2 \mathrm{MPa}$ is $600{ }^{\circ} \mathrm{C}$.

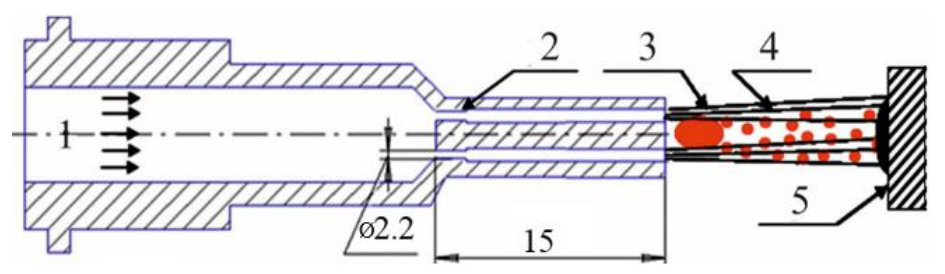

a

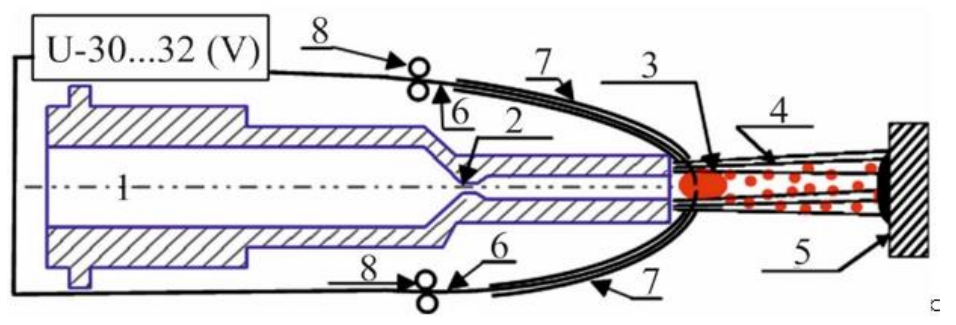

$\mathrm{b}$

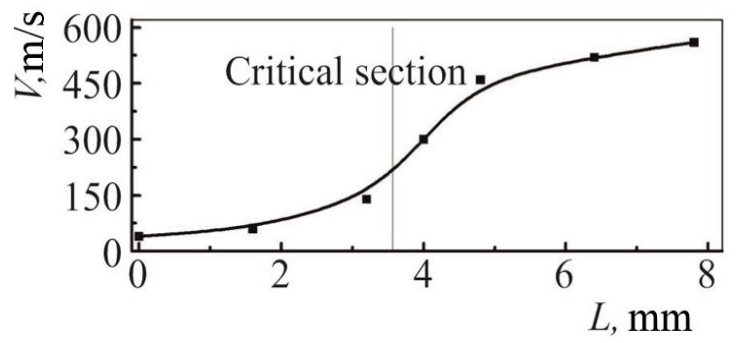

$\mathrm{c}$

Fig. 1 A nozzle schematic (frontal (a) and top (b) views) for obtaining a supersonic flow (1 - air flow, 2 - critical section of a nozzle, 3 - melt of electrode materials, 4 - metal-air flow, 5 - steel substrate with a spray coating, 6 - flux-cored wires,

7 - guide dies, 8 - rollers for wire feed) and a flow rate curve $V$ along a Laval's nozzle length $L$ (c)

To determine the size of the droplets of molten metal, the method of spraying into a snow target was used. Pure snow pressed inside a vessel with a diameter of $300 \mathrm{~mm}$ and a depth of $350 \mathrm{~mm}$ was used as a snow target. A cored wire weighing 150-200 g was sprayed into such a target. After melting the snow, evaporating the water and drying the extracted particles, they were sieved through sieves with various openings $(50 \mu \mathrm{m}, 100 \mu \mathrm{m}, 150 \mu \mathrm{m}, 200 \mu \mathrm{m}, 250 \mu \mathrm{m}$, $300 \mu \mathrm{m}, 350 \mu \mathrm{m}, 400 \mu \mathrm{m}, 450 \mu \mathrm{m}, 500 \mu \mathrm{m})$ using a vibrating machine and each of these fractions was separately weighed. The ratio of the masses of each of the fractions relative to the mass of the whole precipitate was used for determining the percentage of each from all revealed fraction.

The flight velocity of the molten metal droplets $V_{d}$ from the metallizer nozzle to the substrate was determined using two disks rotating on the same shaft at a speed of $50 \mathrm{~s}^{1}$ (Fig. 2). There was a hole in the disk located closer to the metallizer nozzle. The droplets of molten metal could fly through this hole during a spraying process. On the second disk, these droplets left a trace offset from the hole in the first disk. The velocity of the molten metal droplets was determined according to the equation:

$$
V_{d}=2 \pi R_{g} \omega \frac{\Delta l}{l_{0}}
$$

where $R_{g}$ is the radius along which the hole in the first disk rotates relatively to the shaft; $\omega$ rotation velocity of both disks; $l_{0}$ - the distance between the outer edges of both disks $20 \mathrm{~mm}$; 
$\Delta l$ - the distance between the extreme right positions of the hole in the first disk and the spraying spot trace on the second disk.

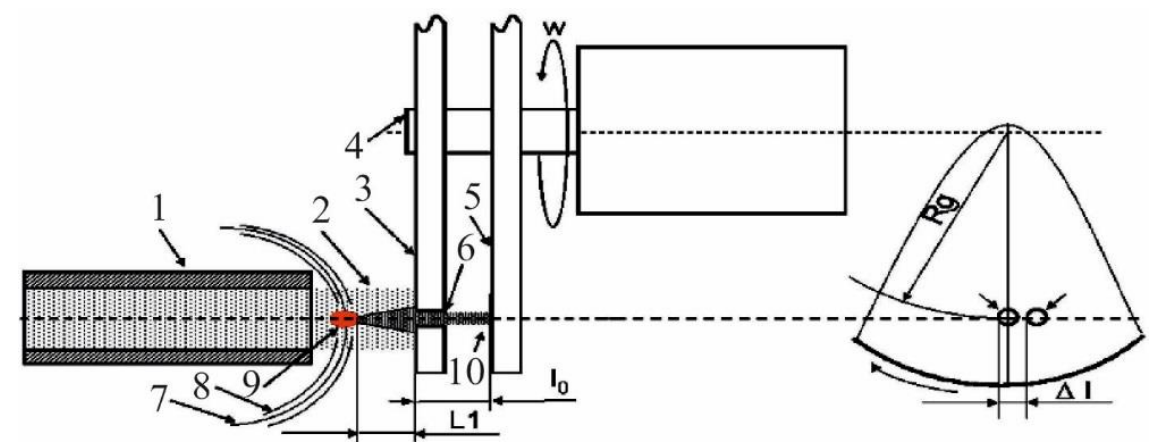

Fig. 2 Test scheme for determining the velocity of molten metal droplets using two disks rotating on the same shaft: 1 - nozzle metallizer; 2 - molten metal droplets; 3, 5 - disks; 4 - rotating shaft; 6 - hole in the first disc diameter 10mm; 7, 8 - electrode wires and guides for their supply to the arc burning zone, respectively; 9 - arc burning zone; 10 - a spot formed by molten metal droplets on the second disk

Only open porosity of the coatings was evaluated in the current study, since namely such porosity determines their corrosion resistance and tribological characteristics. Corrosion environment penetrates over the open pores inside sprayed coatings to the steel substrate. As a result of their interaction, corrosion products are formed and delimitation of the coatings from the substrate took place. During studies the specimens in the form of such coatings by the thickness of $2 \mathrm{~mm}$ after their outlamination from the substrate were used. These specimens were weighed in the air using the electronic analytical balance of KERN ABJ $2204 \mathrm{M}$ type with an accuracy of $10^{4} \mathrm{~g}$, and their mass $M_{0}$ determined. After that, the specimens were infiltrated with kerosene, characterized by a high ability to penetrate into metal through the smallest pores. The penetration time was 30 minutes. Then, the specimens were reweighed to determine the total weight of the outlamination coating and kerosene penetrated into its pores $M_{1}$. The mass of kerosene $M$ inside the pores of the coatings was determined as the difference between $M_{1}$ and $M_{0}: M=M_{1}-M_{0}$.

The kerosene density $\rho$ was taken equal to $0.85 \mathrm{~g} / \mathrm{cm}^{3}$. With account of the density of kerosene, its volume in open pores inside the coatings $V_{1}$ was determined according to the expression: $V_{l}=M / \rho$. After determining the volume of specimen $V_{2}$ (by the volume of distilled water displaced by them when completely immersed in it), the open porosity of the coatings $P$ was estimated from the ratio: $P=\left(V_{1} / V_{2}\right) \times 100 \%$.

The cohesive strength of the obtained coatings was determined on the 5140 steel specimens consisting of two identical halves. Two tubes by $100 \mathrm{~mm}$ long with one-sided thread at the end were used. The thread on the ends of each specimen halves was necessary for their tensile by the machine to failure of coating applied on their surfaces. Before applying the coating on the specimen surface, the opposite edges (with respect to their threaded parts) of their both halves were tightly pressed between themselves using nuts and a rod threaded on both sides (Fig. 3).

The cylindrical surface of such collected specimen was grinded and a $1 \mathrm{~mm}$ thick coating applied on this surface. After that, the specimen was freed from the clamping device and tensiled on an FPZ-10 machine, for determining the force at the fracture moment of the coating along the contact line of both specimen halves. The cohesive strength of the coating was determined as the ratio of the fracture force of such a specimen to the cross area of sprayed layer determined as the fracture surface area in the form of a ring. 


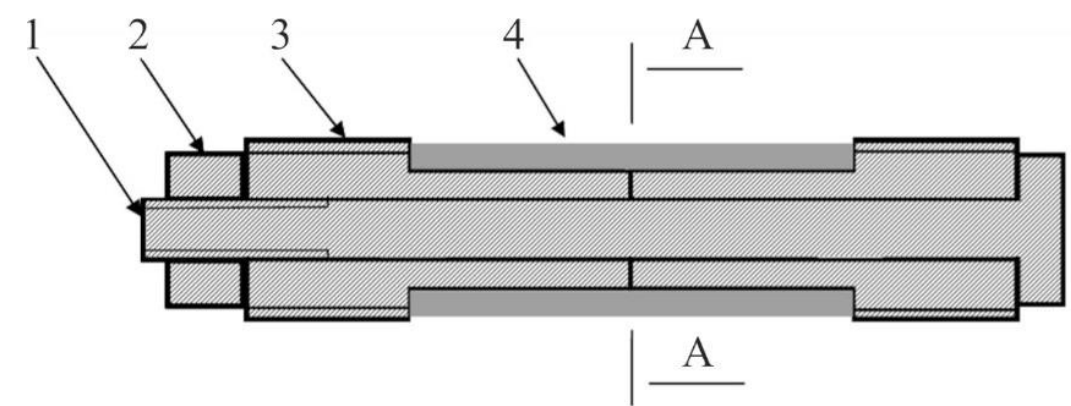

a

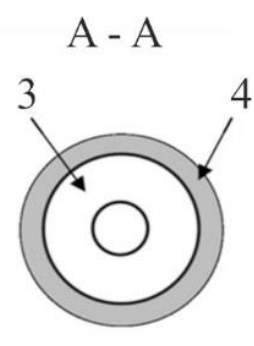

b

Fig. 3 The scheme of the specimen for determining of the cohesive strength of the sprayed coating (a), consisting of two separate parts used as the sprayed substrates (3) which compressed between each other before spraying of coating on their cylindrical surfaces (4) with using of bolt (1) and nut (2) and the view of the specimen cross section in a plane A-A $(b)$ where the fracture of the coating (4) takes place during tensile of specimen on the bursting machine

The residual stresses in the coatings were determined on specimens in the view of SA-29 1060 steel rings with a diameter of $60 \mathrm{~mm}$, a height of $20 \mathrm{~mm}$, a thickness of $4 \mathrm{~mm}$, cut through in one of their axial cross-sections [14]. To the outer cylindrical surface of these rings the ASC with a thickness of $1 \mathrm{~mm}$ were applied. Due to the residual stresses in the coatings, the distance between the edges of the cuts on the steel rings (used as a substrate) was changing as the thickness of the coating increases. In determining the residual stresses, the elastic modules of the steel ring substrate and the sprayed layer (for which it was $70 \mathrm{MPa}$ ) were taken into account.

Abrasive wear tests during the friction with non-rigidly fixed (free) abrasive particles were carried out using the testing device (Fig. 4a).

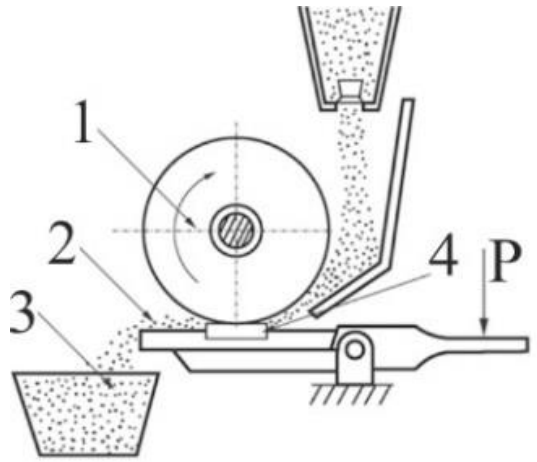

a

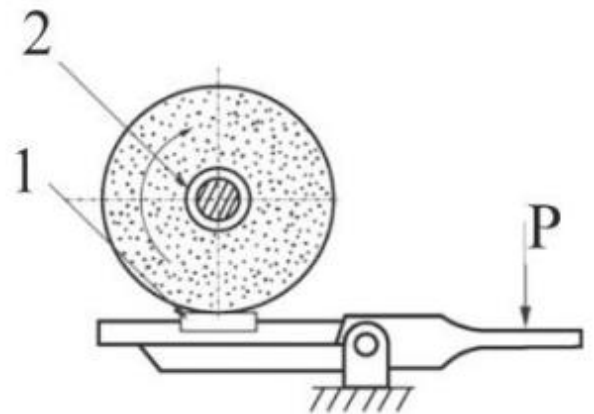

b

Fig. 4 The schemes of the abrasive wear test at using the free abrasive (a: 1 rubber disc,

2 sand, 3 tank for collecting waste abrasive, 4 specimen) and the rigidly

fixed one (b: 1 specimen, 2 abrasive wheel)

A rubber disk profile with a diameter of $48-50 \mathrm{~mm}$ and a width of $13 \mathrm{~mm}$ was maintained using a profiling sample in the form of a flat steel plate with fixed to it and a sanding pelt with grit of 800 . The parameters of this friction mode: load $P=24 \mathrm{~N}$, disk rotation speed $160 \mathrm{rpm}$. The dried and fractionated sand $\mathrm{SiO}_{2}$ (the size of the sand particles varied in the range of the $200 \ldots 1000 \mu \mathrm{m}$ ) was used as abrasive. The abrasive was permanently supplied to the contact area of the rubber wheel with the specimen using a dosing device. In comparison, the wear tests were performed using an abrasive disk with a diameter of $150 \mathrm{~mm}$ and a width of $8 \mathrm{~mm}$ made with electrocorundum (Fig. 4b). The electrocorundum grain size was $250-315 \mu \mathrm{m}$ $(25 \mathrm{~A}, 25 \mathrm{~N})$, the disk speed rotation was $160 \mathrm{rpm}$, the load in the linear contact zone was 15 
$\mathrm{N}$. The specimens wear tested at both schemes was evaluated by their mass loss using an electronic analytical scales of the KERN ABJ $2204 \mathrm{M}$ type ensured the weighing accuracy up to $2 \cdot 10^{4} \mathrm{~g}$.

\section{Experimental techniques}

The flow pressure effect on the structure of coatings. It was experimentally established that at the air pressure 1.2 $\mathrm{MPa}$ at the entrance to the supersonic Laval's nozzle part leads to an increase in the air flow speed at the exit of its nozzle by $\sim 1.9$ times (from 300 to $580 \mathrm{~m} / \mathrm{s}$ ). As a result, the molten metal droplets rate, dispersed by the air flow during spraying of the electrode wires, was increasing from 90 to $210 \mathrm{~m} / \mathrm{s}$, and their average sizes decreasing from 75 to $25 \mu \mathrm{m}$ at the air pressures of the 0.6 and $1.2 \mathrm{MPa}$ correspondently (Fig. 5). The size distribution of the molten metal droplets was also significantly depending on the air flow pressure used to obtain of the ASC (Fig. 6). By using a higher air flow pressure, the narrower size distribution of the molten metal droplets and its essential shift towards smaller sizes was watched. Moreover, reducing the flight time of dispersed droplets from the arc to the substrate due to higher air flow pressure provides them with a higher temperature at the moment of their contact with substrate. The higher the air flow pressure used during ASC formation the more focusing of the air flow and molten metal droplets flow are obtained at the nozzle exit (Fig. 7). As a result, the spraying angles of the air flow and molten metal droplets flow were decreasing from $30^{\circ}$ to $15^{\circ}$.

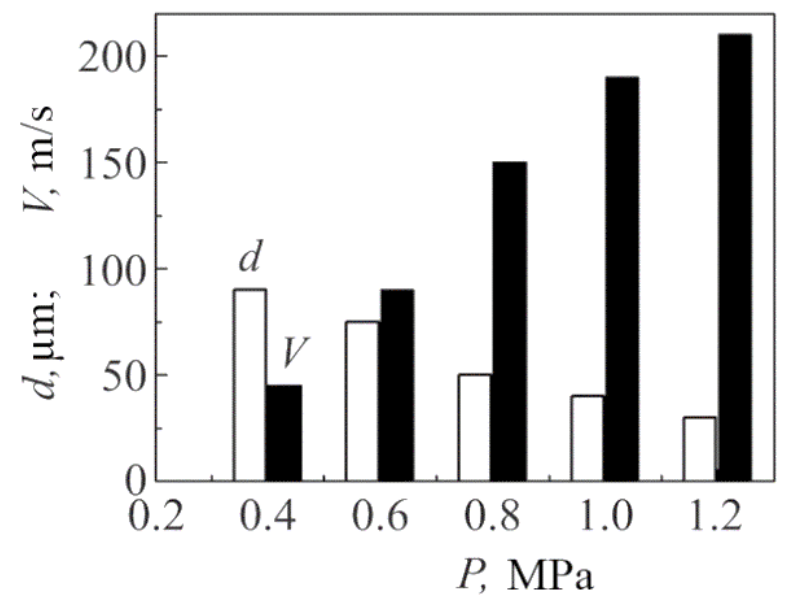

Fig. 5 The effect of the air flow pressure $P$ on the change in the average diameters $d$ (white columns) and rate $V$ (black columns) of the molten metal droplets

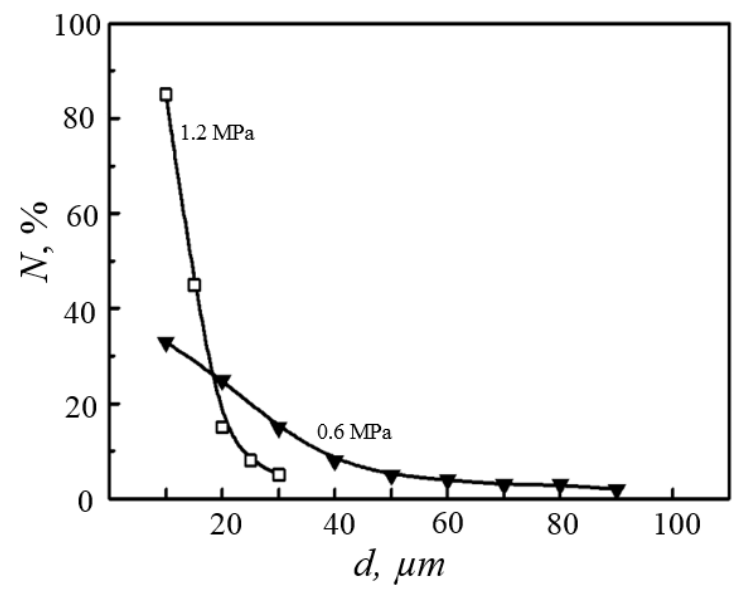

Fig. 6 Fractional distribution by the sizes of melt droplets $d$ obtained by spraying of the CW Cr6B3Al3Mg2 at the air flow pressures $0.6 \mathrm{MPa}$ and $1.2 \mathrm{MPa}$ 


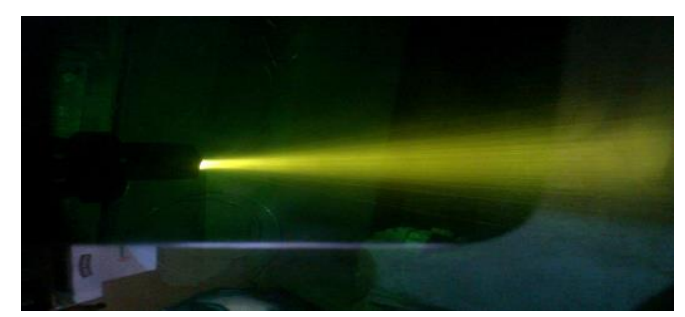

a

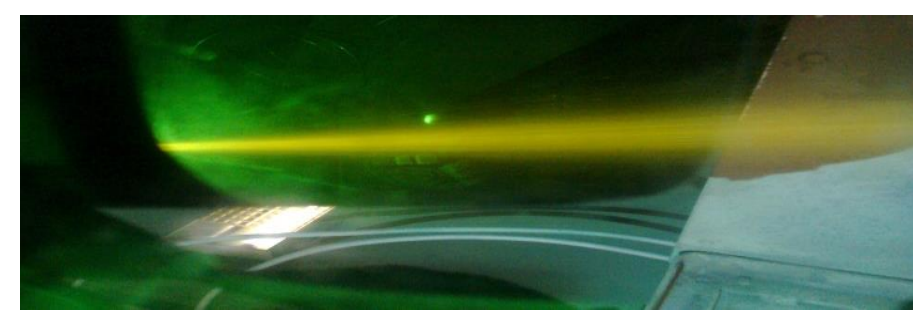

b

Fig. 7 Focusing angles of the air-metal flow on the nozzle exit at the entrance air flow pressure of 0.6 (a) and 1.2 (b) MPa

An increase in the air flow pressure significantly changes the separation conditions of the molten metal droplets from the electrode wires ends (Fig. 8). At the same time, the melting zone of the wires significantly expands, and the current density at their ends decreases. As a result, the metal melt temperature at the electrodes ends decreases (at a pressure of $0.6 \mathrm{MPa}$, this temperature reaches $2000-2200{ }^{\circ} \mathrm{C}$, Fig. $8 \mathrm{a}$, c), but the staying time of the melted particles between their ends increases. This contributes to a more complete dissolution of the hard-tomelt charge components of the $\mathrm{CW}$ in the melt of their steel sheaths and more intensive dispersion of the obtaining melt of electrode wires (Fig. 8b, d). Moreover, this promotes to reduce the droplet sizes, forming the coating.

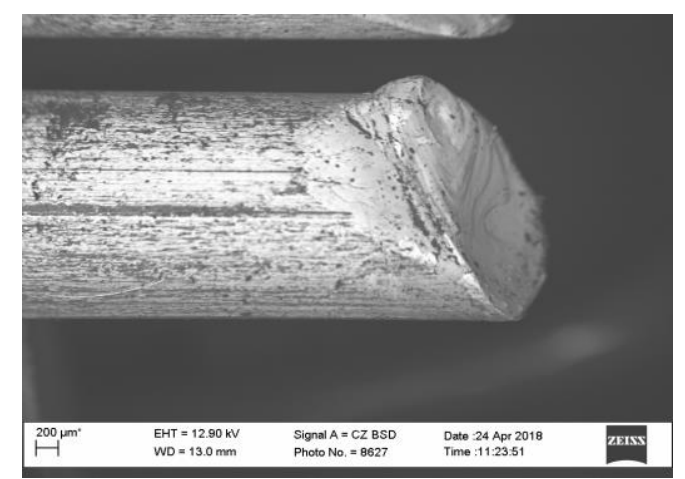

$\mathrm{a}$

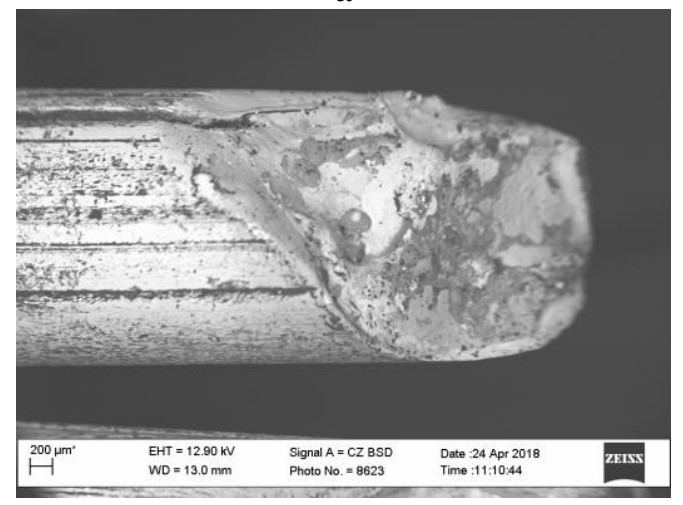

c

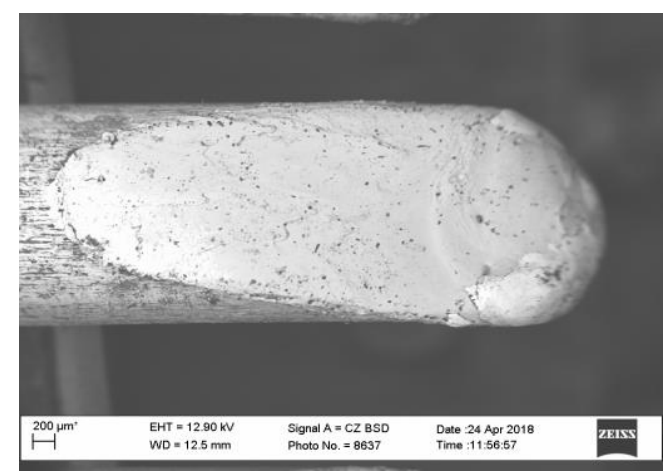

$\mathrm{b}$

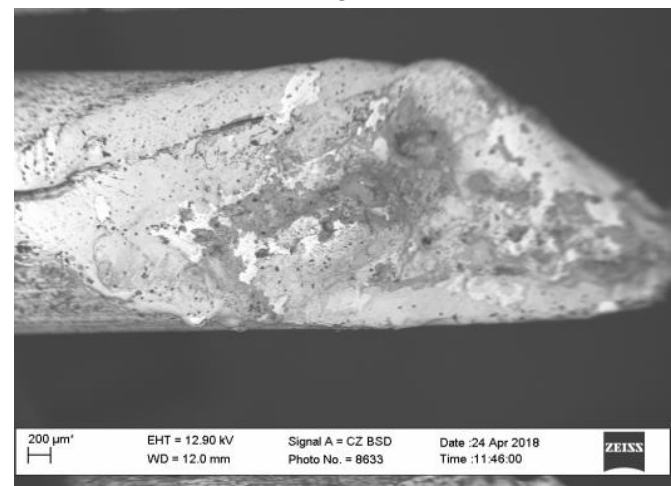

d

Fig. 8 Melted ends of the solid wires from U8 steel $(a, b)$ and of the cored wires of $\mathrm{Cr} 18 \mathrm{~B} 3 \mathrm{Si} 2$ type (c, d) formed after finishing a spraying process at the air flow pressure of $0.6(\mathrm{a}, \mathrm{c})$ and $1.2(\mathrm{~b}, \mathrm{~d}) \mathrm{MPa}$

In particular, at an air pressure of $0.6 \mathrm{MPa}$, the melt droplets with sizes within the ranging from 30 to $90 \mu \mathrm{m}$ are formed (Fig. $9 a$ ), and at a pressure of $1.2 \mathrm{MPa}-10 \ldots 30 \mu \mathrm{m}$ and even smaller (Fig. 9b). Consequently, the results of metallographic studies are agreed with the conclusions of the fractional composition analyze of droplets (Fig. 6). 


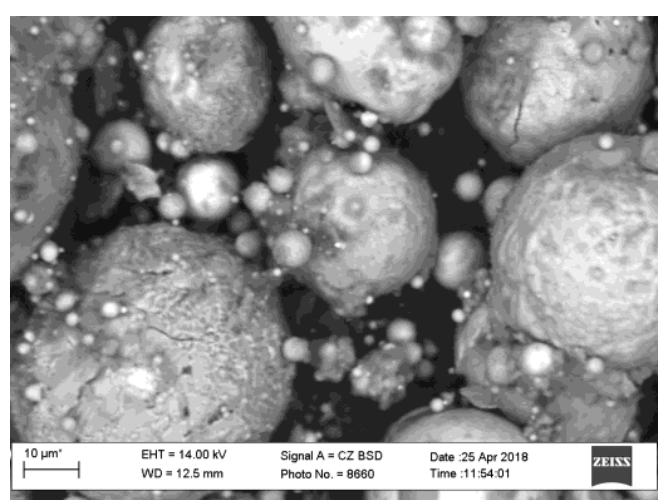

a

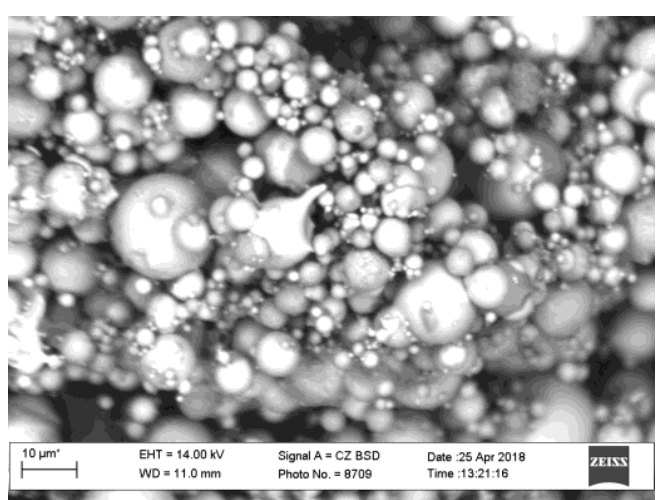

b

Fig. 9 Dimension and shape of solidified of molten metal droplets obtained during a spraying of the CW Cr18B3Si2 at the air flow pressure of 0.6 (a) and 1.2 (b) MPa

During the flight of the dispersed of molten metal droplets to the substrate, the oxide films with different chemical composition are formed on their surfaces. The total contact area of molten metal droplets with the air environment increases with decreasing size of these droplets. As a result, partial or complete oxidation of small droplets is occurred (Fig. 9b). Due to the increase in the amount of oxides in the coating, a composite structure is formed (Fig. $10)$.
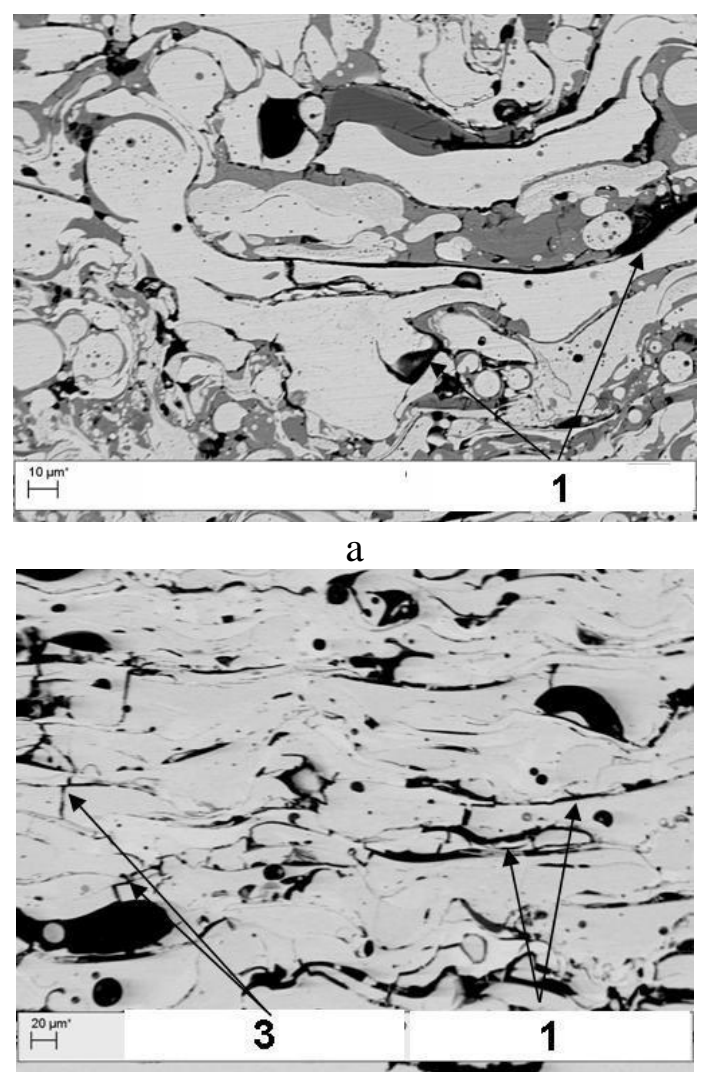

$\mathrm{c}$

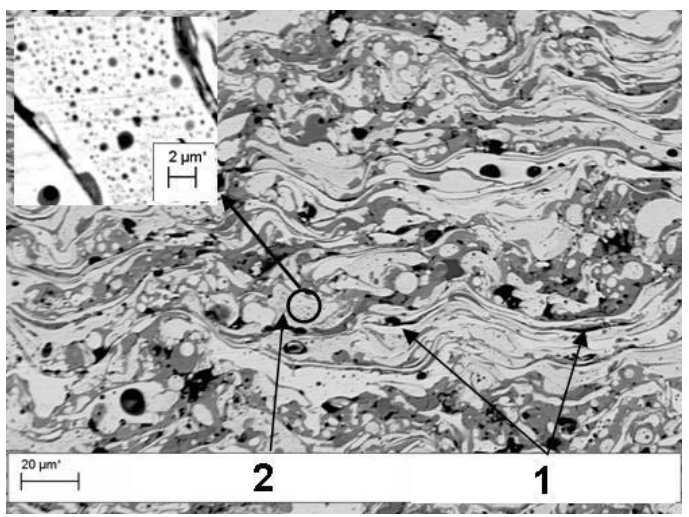

b

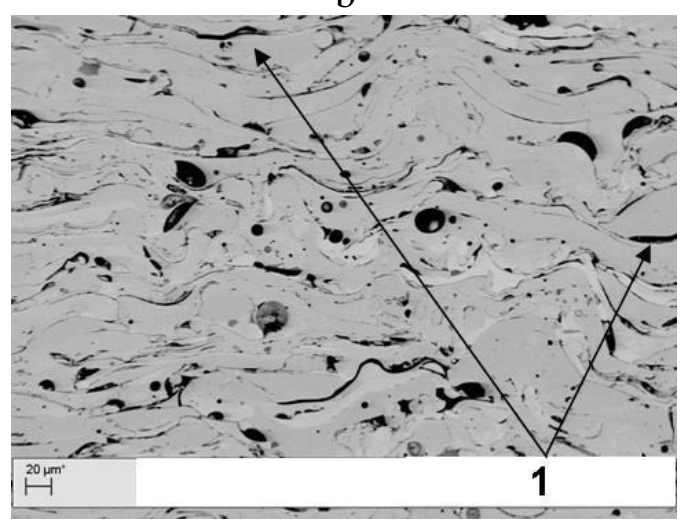

d

Fig. 10. The microstructure of coatings obtained by spraying the solid wire from U8 steel $(\mathrm{a}, \mathrm{b})$ and $\mathrm{CW}$ Cr18B3Si2 (c, d) at the air flow pressures of $0.6(\mathrm{a}, \mathrm{c})$ and 1.2 (b, g) MPa. 1 - oxides located between lamellae; 2 - oxides located inside lamellas; 3 - microcracks formed in the coating 
During the spray, the air flow pressure of $0.6 \mathrm{MPa}$, the amount of the oxide phase in the structure of coating obtained from the solid wire from the U8 steel was $7.0 \mathrm{wt}$. \%, and at a pressure of 1.2 $\mathrm{MPa}$, its content increased 1.7 times and reached $12.0 \mathrm{wt}$. \%. As a rule, the oxide phase was located between the lamellae of the coating (Fig. 10a, b). Although in some cases oxides were also observed inside the lamellae (Fig. 10b). And sometimes the lamellae were also formed from completely oxidized of the molten metal droplets. Compared to the coating obtained by the solid wire from U8 steel in the structure of coatings formed by spraying of the $\mathrm{CW} \mathrm{Cr} 18 \mathrm{~B} 3 \mathrm{Si} 2$ a significant smaller amount of oxide phases was observed (Fig. 10c, d). The similar decrease in oxide phase within coatings structures sprayed by another's cored wires was also confirmed. Moreover, as the pressure of the sprayed air flow increased, the oxide dimensions in the structure of coatings obtained from $\mathrm{CW}$ decreased even more (Fig. 10d).

The amount of oxygen in the coatings obtained from practically all $\mathrm{CW}$ also slightly decreased (Table 2). It was explained by a decrease of the oxidation time of molten metal droplets through reducing - their flight time to the substrate.

Table 2. Oxygen content into coatings depending on the air flow pressure during a spraying process

\begin{tabular}{|c|c|c|c|}
\hline \multirow{3}{*}{ № } & \multirow{3}{*}{ Cored wires type } & \multicolumn{2}{|c|}{ Air flow pressure, $\mathrm{MPa}$} \\
\hline & & 0.6 & 1.2 \\
\hline & & \multicolumn{2}{|c|}{$\begin{array}{l}\text { The oxygen content } \\
\text { into coatings, wt. } \%\end{array}$} \\
\hline 1 & $70 \mathrm{Cr} 18 \mathrm{~B} 3$ & 4.4 & 4.0 \\
\hline 2 & Cr18B3Si2 & 4.3 & 4.0 \\
\hline 3 & Cr6B3Al3Mg2 & 2.5 & 2.0 \\
\hline 4 & 140Cr16B3 & 2.5 & 2.3 \\
\hline 5 & $140 \mathrm{Cr} 14$ & 7.8 & 7.5 \\
\hline 6 & $140 \mathrm{Cr} 14 \mathrm{FeF}$ & 7.4 & 7.2 \\
\hline 7 & 140Cr14Ni2TiAl & 7.0 & 6.5 \\
\hline 8 & 140Cr16B3Ti2Ni2 & 6.0 & 5,2 \\
\hline 9 & U8 & 7.0 & 12.0 \\
\hline
\end{tabular}

The maximum content of oxides in the structures of the ASC was revealed at adding to the charges of $\mathrm{CW}$ such powders as ferrophosphorus (140Cr14FeF), ferrochrome and ferrotitanium (140Cr14Ni2TiAl, 140Cr16B3Ti2Ni2). In these cases, oxides of such elements as $\mathrm{Ti}, \mathrm{Cr}$ and $\mathrm{Fe}$ or their mixtures are predominantly formed in the coating. However, the oxides content in the coatings structure is significantly reduced at addition to the charges of $\mathrm{CW}$ such elements as $\mathrm{B}, \mathrm{Al}$ and $\mathrm{Mg}$. Moreover, their chemical composition also changes. The oxides of $\mathrm{Mg}$ or $\mathrm{Al}$ were predominantly revealed in the structure of such coatings. This is made possible by the aluminothermic restoration of all other oxides to the metal state.

Based on the analysis of the oxygen content in all analysed coatings, the effect of airflow pressure on the mechanical characteristics of arc sprayed coatings was estimated on the coatings (1-3) from the table 2. A coating with a very high content of oxides obtained by spraying of a solid wire from U8 steel was used for comparison.

The air flow effect on the mechanical properties of arc sprayed coatings, obtained from cored wires. The thickness of the soft oxide films in the coating reached $1 \ldots 3 \mu \mathrm{m}$ at the pressure of the spraying air flow of $1.2 \mathrm{MPa}$ (Fig. $10 \mathrm{~b}, d$ ), while at a pressure of $0.6 \mathrm{MPa}$ their thickness reached of $20 \mu \mathrm{m}$ (Fig. 10a,c). The inclusions microhardness values of iron oxides (in the form of magnetite, wustite and hematite) in the coatings sprayed by wire from an 
unalloyed of $\mathrm{U} 8$ steel changed within of $700 \ldots 800 \mathrm{HV}_{0.2}$. These oxides provided an average level of the coating microhardness obtained at an air flow pressure of $0.6 \mathrm{MPa}$, equal to 430 $\mathrm{HV}_{0.2}$ (Fig. 11, column 4). In the coating made using the same wire, but formed at a pressure of 1.2 $\mathrm{MPa}$, a decrease in the size of the plates and oxides was observed, but an increase in their volumetric content. As a result, the average level of microhardness of such coatings increased to $500 \mathrm{HV}_{0.2}$. The average levels of microhardness for the coatings sprayed of $\mathrm{CW}$ 70Cr18B3Si2, CW Cr18B3Si2 and of CW Cr6B3Al3Mg2 at both values of the air flow pressure were practically identical (near $620 \mathrm{HV}_{0.2}$ at the air flow pressure $0.6 \mathrm{MPa}$ and near $800 \mathrm{HV}_{0.2}$ at 1.2 MPa correspondently, Fig. 11, columns 1-3). In other words, the use of fluxcored wires for spraying makes it possible to increase the hardness of the obtained coatings at about $65 \%$ at both air flow pressure (of 0.6 and $1.2 \mathrm{MPa}$ ) compared to the hardness of a coating, obtained by spraying the solid wire of the U8 steel. This is due to the formation of aluminum oxides into the coating structure from the cored wires (their microhardness reaches of the $2000 \mathrm{HV}_{0.2}$ ). A significantly larger scatter of these microhardness values of coatings obtained by spraying with flux-cored wire was observed compared to spraying with wire made of U8 steel. Moreover, the hardness data scattering is reduced at using the higher air flow pressure during spraying.

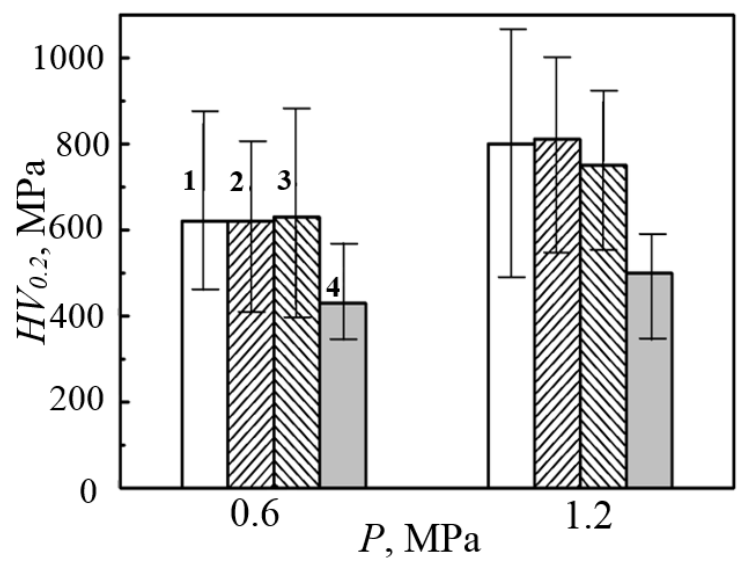

Fig. 11. The average values of the $\mathrm{HV}_{0.2}$ microhardness of coatings formed by spraying the cored wires from CW 70Cr18B3 (1), Cr18B3Si2 (2), Cr6B3Al6Mg2 (3) and the solid wire from U8 steel (4), at the air flow pressure $P$ of 0.6

or 1.2 MPa. The average microhardness values are obtained as a result of 30 measurements.

It is established that the air flow pressure largely determines the porosity of the coatings. As it is shown in the example, the coating from the CW Cr18B3Si2 with increasing of the air flow pressure from 0.6 to $1.2 \mathrm{MPa}$, decreases its total porosity from 8.0 to $2.0 \%$. At the same time, the pore sizes also decreased (from 30 up to $3 \mu \mathrm{m}$ ). The cohesive strength values $\sigma_{C S}$ of the coatings sprayed by the $\mathrm{CW}$ Cr18B3Si2, CW $70 \mathrm{Cr} 18 \mathrm{~B} 3$ and $\mathrm{CW} \mathrm{Cr} 6 \mathrm{~B} 3 \mathrm{Al} 3 \mathrm{Mg} 2$ increased from 1.3 to 2.0 times with an increase in the air flow pressure from 0.6 to $1.2 \mathrm{MPa}$ (Fig. 12a). The existence of strong bonds between lamella into coatings and the appearance of thin oxide films $(0.5 \mu \mathrm{m}-5.0 \mu \mathrm{m})$ of large length between them, playing the role of strengthening components of coatings formed at a pressure of $1.2 \mathrm{MPa}$ (Fig. 10d), are responsible for increasing the adhesion strengths. In addition, microcracks, revealed in the structure of coatings, sprayed at the air flow pressure of $0.6 \mathrm{MPa}$ (Fig. 10c), disappeared from the structure of the coatings sprayed at a pressure of $1.2 \mathrm{MPa}$ (Fig. 10d). However, the residual tensile stresses in these coatings substantially are also increased (Fig. 12b).

The molt metal droplets decrease in size and, as a result, contribute to the formation of residual tensile stresses in the coatings during their cooling and crystallization at the contact 
with a cold substrate (Fig. 12b). The relaxation of these stresses occurs behind two mechanisms $[15,16]$. According to the first of them, the residual stress relaxation in homogeneous solid coatings (under absence in their structure of ductile structural components) occurs through the formation of the microcracks network in them (Fig. 10c). This is typical for coatings, obtained by spraying of the CW Cr18B3Si2 and CW 70Cr18B3. During the spraying of coatings with the use of the air flow at higher pressure, their cohesive strength levels increase (Fig. 12a), microcracks do not form into them and residual stress relaxation does not occur according to the mechanism described above.

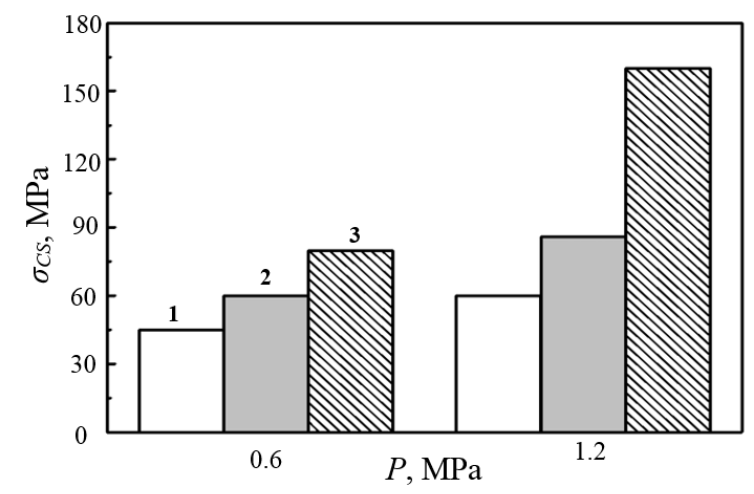

a

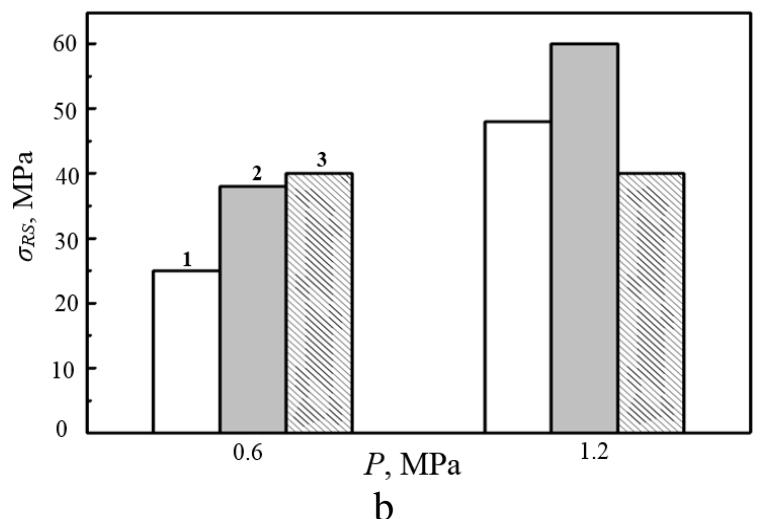

Fig. 12 Cohesive strength $\sigma_{C S}(a)$ and residual tensile stresses $\sigma_{R S}(b)$ for the coatings obtained by spraying CW 70Cr18B3 (1), CW Cr18B3Si2 (2)

and $\mathrm{CW}$ Cr6B3Al3Mg2 (3) at two values of the air flow pressures (0.6 MP and 1.2 MPa)

The residual stress relaxation is realized according to another mechanism on the heterogeneous solid coating from the $\mathrm{CW}$ Cr6B3 $\mathrm{Al} 3 \mathrm{Mg} 2$ based on the presence of hard and soft plastic lamellas in its structure (Fig. 10d). In this case, the stress relaxation occurs as a result of plastic deformation inside the soft lamellae [17, 18]. As a result, the cohesion strength level of this coating increase (Fig. 12a) and the residual tensile stress value in it simultaneously decrease (Fig. 12b). The abrasive wear tests showed that as a result of increasing the air flow pressure during the formation of coatings from all cored wires, and from solid wire from U8 steel, their wear resistance is increased at tests with a fixed (Fig. $13 a$ ), and with unfixed abrasive (Fig. 13b).

The wear resistance of the coatings depends on the values of their cohesive strength, the levels of residual tensile stresses and the structure of the coatings (namely, the presence of microcracks in the coatings) $[19,20]$. 


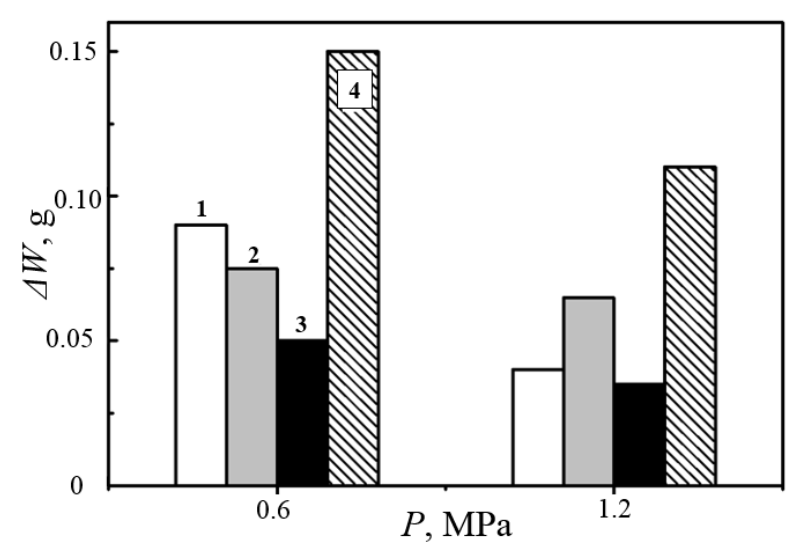

a

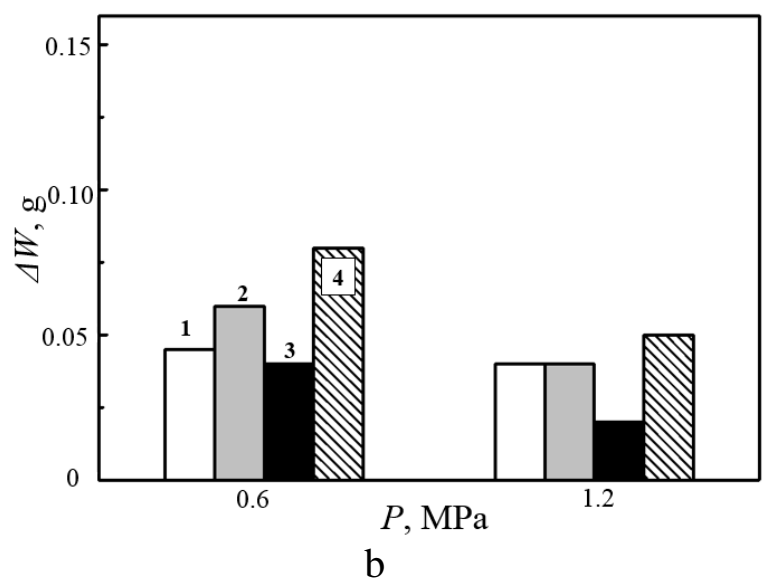

Fig. 13 The values of the weight loss $\Delta \mathrm{W}$ of specimens with coatings obtained by spraying CW 70Cr18B3 (1), CW Cr18B3Si2 (2),

CW Cr6B3Al3Mg2 (3) and solid wire from U8 steel (4) under the air flow pressures of 0.6 and $1.2 \mathrm{MPa}$, after friction test using fixed (a) and unfixed (b) abrasive

\section{Conclusions}

It was established that with an increase in the air flow pressure from 0.6 to $1.2 \mathrm{MPa}$ during the spraying of coatings, the velocity at the exit from the supersonic Laval's nozzle increases to 300 and to $580 \mathrm{~m} / \mathrm{s}$, respectively. It was determined that the speed of dispersed molten metal drops increases in this case to 90 and to $210 \mathrm{~m} / \mathrm{s}$, correspondently. With an increase in the pressure of the sprayed air flow from 0.6 to $1.2 \mathrm{MPa}$, the thickness of the lamellae in the coatings decreases and a larger amount of oxide phase forms. As a result, the hardness, wear resistance, and cohesive strength of the arc spray coatings from the cored wires increase.

\section{References}

[1] Wielage, B., Pokhmurska, H., Student, M., Gvozdeckii, V., Stupnyckyj, T., Pokhmurskii, V. "Iron-based coatings arc-sprayed with cored wires for applications at elevated temperatures", Surface and Coatings Technology 220, pp. 27 - 35, 2013. DOI: 10.1016/j.surfcoat.2012.12.013

[2] Pokhmurskii, V., Student, M., Gvozdeckii, V., Stypnutskyy, T., Student, O., Wielage, B. "Arc-sprayed iron-based coatings for erosion-corrosion protection of boiler tubes at elevated temperatures", Journal of Thermal Spray Technology 22, pp. 808 - 819, 2013. DOI: $10.1007 / \mathrm{s} 11666-013-9921-\mathrm{z}$

[3] Student, M. M., Pokhmurs'ka, H. V., Hvozdets'kyi, V. M., Holovchuk, M. Ya., Romaniv, M. S. "Effect of high-temperature corrosion on the gas-abrasive resistance of electric-arc coatings", Materials Science 45(4), pp. 481 - 489, 2009. DOI: 10.1007/s11003-010-9205-4

[4] Dallaire, S., Levert, H. "Development of cored wires for improving the abrasion wear resistance of austenitic stainless steel", Journal of Thermal Spray Technology 6 (4), pp. 456 - 461, 1997. DOI: 10.1007/s11666-997-0031-7

[5] Liu, S.-G., Wu, J.-M., Zhang, S.-C., Rong, S.-J., Li, Z.-Z. "High temperature erosion properties of arc-sprayed coatings using various cored wires containing Ti-Al intermetallics", Wear 262 (5 - 6), pp. 55 - 61, 2007. DOI: 10.1016/j.wear.2006.06.021 
[6] Ivanov, Y. F., Kormyshev, V. E., Gromov, V. E., Konovalov, S. V., Teresov A. D., Semin, A. P "Structural phase states and properties of the layer surfaced on low-carbon steel with $\mathrm{Fe}-\mathrm{C}-\mathrm{Cr}-\mathrm{Nb}-\mathrm{W}$ powder-core wire followed by electron-beam processing", J. Synch. Investig. 11, pp. 933 - 939, 2017. DOI: 10.1134/S1027451017050044

[7] Student, M., Vojtovych, A., Pokhmurska, H., Maruschak, O., Student, O., Maruschak, P. "Mechanical characteristics and wear resistance of the cladding layers obtained by melting of cored wires with simultaneous vibration of substrate", Strojnícky časopis Journal of Mechanical Engineering 69 (1), pp. 109 - 122, 2019. DOI: 10.2478/scjme2019-0009

[8] Arizmendi-Morquecho, A., Campa-Castilla, A., Almicar, J., Martinez, A., Gutiérrez, G. V., Judith, K., Bello, M., López, L. L. "Microstructural characterization and wear properties of Fe-based amorphous-crystalline coating deposited by twin wire arc spraying", Advances in Materials Science and Engineering, 2014. Article ID 836739, DOI: $10.1155 / 2014 / 836739$

[9] Student, M., Dzioba, Yu., Hvozdets'kyi, V., Pokhmurska, H., Wielage, B., Grund, T. "High-temperature corrosion of electric-arc coatings sprayed from powder core wires based on the Fe-Cr-B-Al system", Materials Science 44 (5), pp. 693 - 699, 2008. DOI: $10.1007 / \mathrm{s} 11003-009-9131-5$

[10] Stupnyts'kyi, T. R., Student, M. M., Pokhmurs'ka, H. V., Hvozdets'kyi, V. M. "Optimization of the chromium content of powder wires of the $\mathrm{Fe}-\mathrm{Cr}-\mathrm{C}$ and $\mathrm{Fe}-\mathrm{Cr}-\mathrm{B}$ systems according to the corrosion resistance of electric-arc coatings", Materials Science 52 (2), pp. 165172, 2016. DOI: 10.1007/s11003-016-9939-8

[11] Sunde, A. Properties of thermal sprayed coatings for internal use in pipes and bends, Master thesis, Supervisor: Roy Johnsen Trondhein: Norwegian University of Science and Technology Technology, 101 p., 2015.

[12] Korobov, Yu., Filippov, M., Makarov, A., Malygina, I., Soboleva, N., Fantozzi, D., Andrea, M., Koivuluoto, H., Vuoristo, P. "Arc-sprayed fe-based coatings from cored wires for wear and corrosion protection in power engineering", Coatings 8 (2), 71, 2018. DOI: $10.3390 /$ coatings 8020071

[13] Jablonská, J., Kozubková, M., Zavadilová, B., Zavadil, L., Fialová, S. "The investigation of the cavitation phenomenon in the laval nozzle with full and partial surface wetting" Strojnícky časopis - Journal of Mechanical Engineering 67 (1), pp. 55 - 68, 2017. DOI: $10.1515 /$ scjme-2017-0006

[14] Pokhmurs'ka, H., Student, M., Hvozdetskyi, V., Stupnytskyi, T., Posuvailo, V. "The influence of size and speed of drops on the structure and properties of electric-ARC sprayed coatings", Proceedings of the International Thermal Spray Conference and Exposition, ITSC 2017, Dusseldorf, Germany, 7-9 June 2017, N.Y.: Curran Associates, Inc., Vol. 2, pp. 1031 - 1034, 2017.

[15] Gurvich, L. V., Veyts, I. V., Medvedev, V. A., Khachkuruzov, G. A., Yungman, V. S., Bergman, G. A., Baybuz, V. F., Iorish, V. S., Yurkov, G. N., Gorbov, S. I., et al. Thermodynamic Properties of Individual Substances; Hemisphere Publishing Corp.: New York, NY, USA, 1989, Vol. 1, Part 2, 340 p., 1989.

[16] Konovalov, S. V., Kormyshev, V. E., Gromov, V. E., Ivanov, Yu. F., Kapralov, E. V., and Semin, A. P. "Formation features of structure-phase states of $\mathrm{Cr}-\mathrm{Nb}-\mathrm{C}-\mathrm{V}$ containing coatings on martensitic steel", J. Synch. Investig. 10 (5), pp. 1119 - 1124, 2016. DOI: $10.1134 / \mathrm{S} 1027451016050098$ 
[17] Brezinová, J., Viňáš, J., Maruschak, P. O., Guzanová, A., Draganovská, D., Vrabel', M. "Sustainable renovation within metallurgical production", RAM-Verlag, Lüdenscheid, Germany, 215 p., 2017.

[18] Guzanová, A., Brezinová, J., Bronček, J., Maruschak, P., Landová, M. "Study of selected properties of coatings devoted to extreme tribo-corrosive conditions", Materials Science Forum 818, pp. 32 - 36, 2015. DOI: 10.4028/www.scientific.net/MSF.818.32

[19] Buketov, A. V., Brailo, M. V., Yakushchenko, S. V., Sapronov, O. O., Smetankin, S. O. "The formulation of epoxy-polyester matrix with improved physical and mechanical properties for restoration of means of sea and river transport ", Journal of Marine Engineering \& Technology, 2018. DOI: 10.1080/20464177.2018.1530171

[20] Kindrachuk, M. V., Dushek, Y. Y., Luchka, M. V., Gladchenko, A. N. "Evolution of the structure and properties of eutectic coatings during friction", Powder Metallurgy and Metal Ceramics 34 (5 - 6), pp. 321 - 326, 1995. DOI: 10.1007/BF00560139 